\title{
Magnetic and Thermal Analysis of a Water-cooled Permanent Magnet Linear Synchronous Motor
}

\author{
Xinmin Zhang*, Qinfen Lu*, Chuanying Cheng*and Yunyue Ye*
}

\begin{abstract}
The water-cooled Permanent Magnet Linear Synchronous Motor (PMLSM) has a wide range of applications due to high efficiency, high thrust force density and high acceleration. In order to ensure normal operation and maximum output, both the magnetic and thermal performance are vital to be considered. Based on ANSYS software, electromagnetic and thermal finite-element analysis (FEA) models of a 14-pole, 12-slot water-cooled PMLSM are erected adopting suitable assumptions. Firstly, the thrust force and force ripple with different current densities are calculated. Secondly, the influence of different water flow on the motor heat dissipation and force performance under different operationional conditions are investigated and optimized. Furthermore, for continuous operation, the temperature rise and thrust feature are studied under the rated load $8 \mathrm{~A}$, the proper temperature $120^{\circ} \mathrm{C}$ and the limited temperature $155^{\circ} \mathrm{C}$. Likewise, for short-time operation, the maximum duration is calculated when applied with a certain large current. Similarly, for intermittent operation, load time as well as standstill time are determined with the optimal current to achieve better thrust performance.
\end{abstract}

Keywords: Thermal analysis, Force performance, Operation condition, Water flow

\section{Introduction}

The permanent magnet linear synchronous motor (PMLSM) has been widely used due to its superiority in high thrust force density, high efficiency, high acceleration etc, however its performance is deeply influenced by the temperature which depends on the produced copper and iron loss. Therefore, thermal analysis is also necessary at the initial stage of the motor design, which predicts whether or not the desired results can be achieved at different working conditions.

With the increasing needs for miniaturization, energy efficiency, and cost reduction, many scholars are currently carrying out thermal analysis. The analysis of the thermal fields, temperature distribution can be obtained through thermal resistance models, finite-element analysis (FEA) or computational fluid dynamics (CFD), which can ultimately be verified through experimental results [1]-[2]. In fact, the electromagnetic design and thermal design need to be calculated together due to close link and interdependence. For example, the electromagnetic analysis of copper loss

\footnotetext{
College of Electrical Engineering, Zhejiang University, P.R.

China.(847643774@qq.comluqinfen@zju.edu.cn,

sucwaycheng@yahoo.cn,yeyunyue@yahoo.com.cn)

Received13 October 2012; Accepted 10 November 2012
}

calculation depends on the temperature, and vice versa [3]. However, to water-cooled PMLSM, few articles focus on the impact of the water flow or mention the quantitative analysis. It is clear that a larger water flow leads to greater noise, pressure and requires a stronger mechanical structure of the motor, but a small water flow will yield a higher temperature rise.

This paper analyzes and compares thermal and force performance of a 14-pole, 12-slot water-cooled PMLSM with differing water flow under continuous duty, short-time duty and intermittent duty. Based on magnetic and thermal analysis jointly, the impact of the water flow on the motor heat dissipation and thrust characteristics is researched, which provides a basis for the preliminary design and advanced operation of the motor. The appropriate volumetric flow of water is able to be identified, with which the motor can produce a small temperature rise at the maximum allowed operating current.

Moreover, this article analyzes thermal and thrust properties under three different operation conditions. Firstly, as to continuous duty, the final thermal state can be reached due to the long load time and three qualifications are considered particularly: the rated load $8 \mathrm{~A}$, the appropriate temperature of $120^{\circ} \mathrm{C}$ and the maximum temperature of $155^{\circ} \mathrm{C}$. Secondly, as to short-time duty, the final thermal 
state is absent with the short load time and the long subsequent zero-current break. Specially, the maximum duration is calculated when applied with a certain large current simultaneously assuring that the maximum temperature does not exceed $155^{\circ} \mathrm{C}$. Finally, as to intermittent duty, the motor heats up during the load time with constant current and then cools down while at the standstill time with no current feed. After a few cycles, the temperature oscillates between a constant maximum value, specialized for $120^{\circ} \mathrm{C}$ in the paper, and a constant minimum value. The optimal current as well as load time and standstill time can be calculated at values with which the minimum ratio of thrust ripple and thrust can be obtained.

\section{Magnetic Analysis}

Fig. 1 shows the simplified electromagnetic FEA model of this 14-pole, 12-slot water-cooled PMLSM. The permanent magnet is stationary, called the stator and the armature is moving, called the mover. The simplification is mainly neglecting the notch insulation, slot insulation and winding insulation of the actual motor, which only affects the thermal analysis, not the electromagnetic analysis.

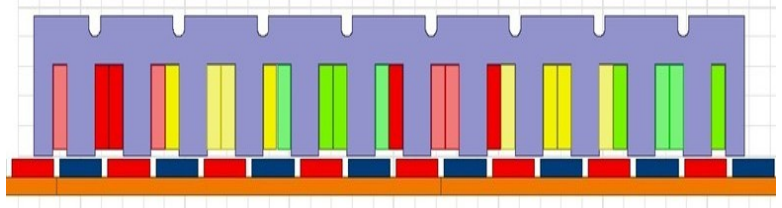

Fig. 1. The simplified electromagnetic FEA model

Through the electromagnetic simulation, thrust and thrust ripple under different current densities are calculated, as shown in Fig.2. Thrust appears as nearly a linear growth before a current density of 14 , while afterwards emerges as a gradual increase mainly due to the influence of the armature reaction and magnetic saturation. Force ripple appears as a remarkable growth after a current density of 14 Apparently, it is not possible to achieve the desired infinitely large thrust and small thrust ripple by increasing current density without limit. According to practical requirements, thrust performance and temperature rise, a reasonable current density can be selected. It is worth noting that the simulation uses current density as a variable and the current density is 0.926 times the current in the FEA model. Thus, the relationship between thrust, thrust ripple and current can be easily received.

Losses of various parts of the motor can be further calculated. In the subsequent thermal analysis, the copper loss can be solved from the following formula:

$$
P_{c u}=3 I^{2} R_{T}
$$

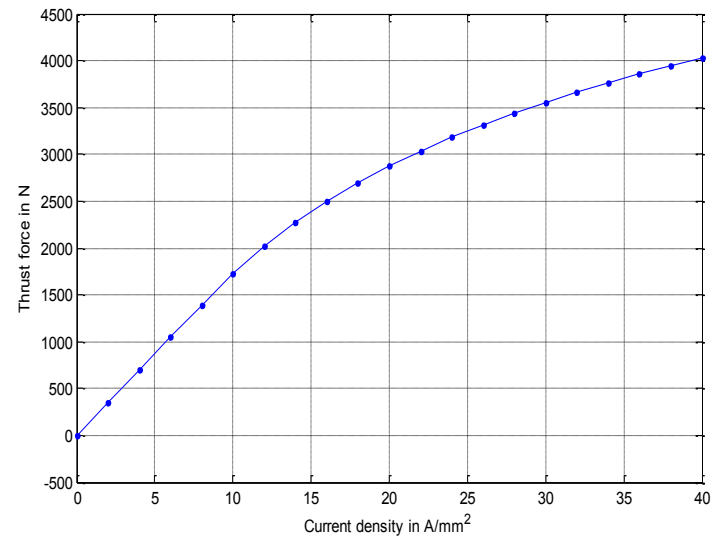

(a) Thrust force

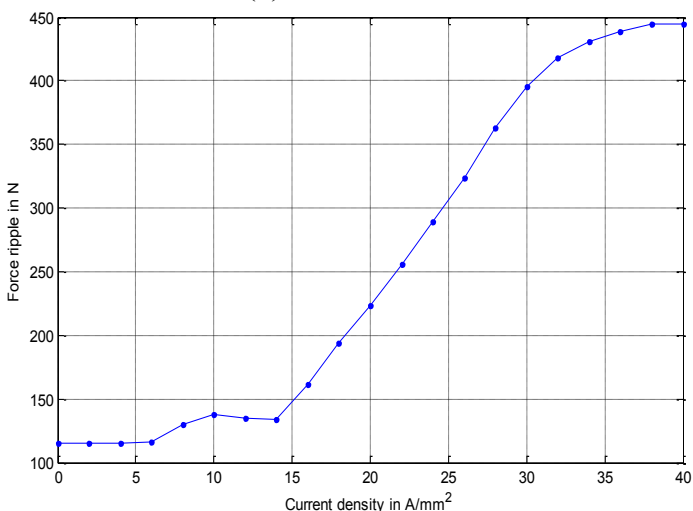

(b) Thrust ripple

Fig. 2. Thrust force and ripple at different current density

where $I$ is the phasing current, $R_{T}$ is the resistance of winding. The calculation of copper loss considers how the impact of temperature varies on resistance changes:

$$
R_{T}=R_{20}[1+a(T-20)]
$$

where $\alpha$ is the temperature coefficient equaling to 0.00393 $1 / \mathrm{K}$ for copper, $R_{20}$ is line resistance of the winding at $20{ }^{\circ} \mathrm{C}$ equaling to $4.367 \Omega$ in this motor, $T$ is the winding temperature.

In the case of the rated current $8 \mathrm{~A}$, the value of copper loss can be computed as $1036.22 \mathrm{~W}$ while the temperature of winding approaches $80^{\circ} \mathrm{C}$ with the water flow of $4 \mathrm{~L} / \mathrm{min}$. However, based on magnetic analysis, the loss of armature core is approximately $37 \mathrm{~W}$, the loss of stator steel plate is about $1.66 \mathrm{~W}$; as can be seen, the iron loss can be negligible relative to the copper loss. Therefore, in the coming thermal analysis, the copper loss is adopted as the only one ideal heat source. 


\section{Thermal Analysis}

\subsection{Thermal Model Setup}

Based on some proper assumptions and the symmetry of the motor, half of the thermal FEA model is established, shown in Fig.3. The pipes with a diameter of $5.5 \mathrm{~mm}$ are uniformly distributed at the top of the mover, connected together in series from one end of the motor to the other end. Coil wires, composed of multiple turns of wire, are modeled as a bulk structure whose area is equal to bare copper. In an actual motor, copper is surrounded by electrical insulation and then coated with adhesive material, finally being wrapped in an insulation sheet and filled with epoxy resin in a notch. Because of the large temperature gradient in the region of insulation, known from the thermal analysis results, the slot needs to be divided in detail in the FEA model. The materials of different motor parts as well as their thermal performance parameters are given in Table $1[4]$.

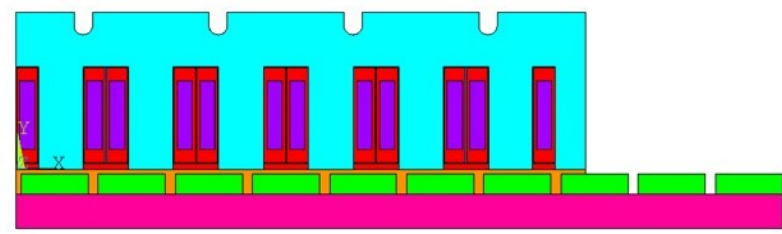

Fig. 3. The simplified thermal FEA model

Table1. Material properties

\begin{tabular}{|l|c|c|c|c|}
\hline \multicolumn{1}{|c|}{ Item } & Material & $K(\mathrm{~W} / \mathrm{mK})$ & $\rho\left(\mathrm{Kg} / \mathrm{m}^{3}\right)$ & $\left.C_{p}\left(\mathrm{~J} / \mathrm{Kg}^{*} \mathrm{~K}\right)\right)$ \\
\hline Mover core & $\begin{array}{c}\text { Silicon } \\
\text { steel }\end{array}$ & 66.1 & 7800 & 434 \\
\hline Winding & $\mathrm{Cu}$ & 385 & 8900 & 380 \\
\hline $\begin{array}{l}\text { Electrical } \\
\text { insulation } \\
\text { /adhesive } \\
\text { /notch }\end{array}$ & Epoxy & 0.8 & 1800 & 900 \\
\hline $\begin{array}{l}\text { Slot } \\
\text { insulation }\end{array}$ & $\begin{array}{c}\text { Insulati } \\
\text { on sheet }\end{array}$ & 0.18 & 930 & 1340 \\
\hline Stator steel & $\begin{array}{c}\text { Steel } \\
1018\end{array}$ & 45 & 7800 & 460 \\
\hline Magnet & N38SH & 8.949 & 7500 & 502 \\
\hline Air gap & Air & 0.0259 & 1.205 & 1005 \\
\hline
\end{tabular}

To simplify thermal analysis, basic assumptions are proposed as follows:

1) Environmental temperature basically maintains $23^{\circ} \mathrm{C}$. Water temperature rise between the import and export is provided by the supplier.

2) Convection film coefficients of boundaries mainly adopt the average values calculated from analytical formulas except that on the edge of the mover top.

3 ) Thermal conductivity in the direction of silicon steel stack thickness is much smaller, which can be neglected, than that within silicon steel. The impact of the end windings on the temperature distribution is ignored so as to convert the 3D model into $2 \mathrm{D}$.

4) Only conduction is considered in the air gap although actually some air comes in and out of the region, because the air gap is very small and convection by buoyancy with a hotter top surface is very weak.

5) Copper loss is regarded as the only heat source.

\subsection{Relevant Formulas and FEA Process}

In general, the temperature differences between surfaces are not very high and the allowable temperature of motor material does not exceed $200{ }^{\circ} \mathrm{C}$; thus, heat transfer by radiation can be ignored [5]. Obviously, thermal conduction play a role on heat dissipation inside the motor and convection affects the boundary. In a 2D coordinate system, when thermal conductivity is constant, the equation of transient heat conduction is simply given by [4]:

$$
\rho c \frac{\partial T}{\partial t}=\lambda\left(\frac{\partial^{2} T}{\partial x^{2}}+\frac{\partial^{2} T}{\partial y^{2}}\right)+q_{v}
$$

Where $T$ is the temperature, $q_{v}$ is the heat generation per unit volume, $\rho$ is the density, $c$ is the specific heat capacity, and $\lambda$ is the thermal conductivity.

FEA has a wide range of applications in initial design because any device geometry can be modeled and computers instead of manual calculation conveniently reach the outcome, though it is demanding in terms of model setup and computational time. FEA can only simulate conduction heat transfer in solid components, so the convective film coefficient, a parameter vital and difficult to be determined accurately, needs to be estimated first from analytical/empirical algorithms before solving the model [3]. There are three convection modes in the model: forced water-cooled convection on the edges of pipes, forced air-cooled convection on the edges of the mover and natural convection on the edges of the stator.

Forced water-cooled convection, removing about 90 percent of the arising heat under rated conditions, has a significant influence on temperature rise of the entire motor due to a considerable convection film coefficient. As a result, the average steady temperature of the winding without water-cooling is $1200^{\circ} \mathrm{C}$ at the rated current $8 \mathrm{~A}$ and 
the max allowed current is $4.43 \mathrm{~A}$ with a temperature limit of $120^{\circ} \mathrm{C}$, but it decreases to approximately $90{ }^{\circ} \mathrm{C}$ with water-cooling. The water-cooled convection coefficient can be remarkably influenced by the wall temperature of the water pipe, which needs to be adjusted constantly according to the simulation results. Under different levels of water flow, water temperature rise of the import and export directly use vendor-supplied test data, as shown in Table 2.

Table 2. Temperature rise

\begin{tabular}{|l|c|c|c|c|c|c|}
\hline Volumetric flow(L/min) & 1 & 2 & 3 & 4 & 5 & 6 \\
\hline Temperature increase $\left({ }^{\circ} \mathrm{C}\right)$ & 12 & 7 & 4.8 & 3.6 & 3 & 2.4 \\
\hline
\end{tabular}

It is worth noting that the ambient temperature should be at most bigger than the intake water temperature by $3^{\circ} \mathrm{C}$ to protect the areas close to the motor from condensation, although the lowest intake temperature is possible for the highest power density. Therefore, the intake temperature is specified to $20^{\circ} \mathrm{C}$. Reynolds exceeds $1 \times 10^{4}$ with different water flow except at 1 or 2 volumetric flow. But the flow is entirely regarded as turbulent because of the curved tubes and continuous perturbations by motion. The forced watercooled film coefficient can be obtained from the following correlation [4]:

$$
N_{u f}=\frac{h d}{\lambda_{f}}=0.023 R_{e f}^{0.8} P_{r f}^{1 / 3}\left(u_{f} / u_{w}\right)^{0.14}
$$

Where $\mu_{f}$ and $\mu_{w}$ are fluid dynamic viscosities under fluid temperature and wall temperature, $d$ is the pipes diameter.

As to forced air-cooled convection, the temperature of the surface has little effect on the film coefficient, which almost remains unchanged under different levels of water flow. On the upper edge of the mover, the heat transfer coefficient changing with coordinate $x$ is imposed in order to reflect the highest temperature part in the middle of the motor and the hottest point. Then, average convection film coefficient is applied on the right edge of the mover, which is slightly smaller than the actual value since the surface is perpendicular to the wind direction [1]. The Reynolds number does not exceed $3 \times 10^{5}$ under different levels of water flow, so the air flow is considered to be laminar flow. The forced air-cooled film coefficient can be achieved from the following correlation [4]:

$$
N_{u x}=\frac{h_{x} x}{\lambda}=0.332 R_{e x}^{1 / 2} P_{r}^{1 / 3}
$$

Natural convection has an extremely small influence on the temperature rise of the entire motor because of a pretty small film coefficient. The film coefficient needs to be adjusted constantly based on the actual surface temperature which has a big effect on it. There exist three relative formulas as follows to calculate the average natural film coefficient [4].

For upper surface of the flat plate:

$$
\overline{N_{u}}=\frac{h l}{\lambda}=0.54\left(G_{r} P_{r}\right)^{1 / 4}
$$

For lower surface of the flat plate:

$$
\overline{N_{u}}=\frac{h l}{\lambda}=0.58\left(G_{r} P_{r}\right)^{1 / 5}
$$

For surface of vertical plate:

$$
\overline{N_{u}}=\frac{h l}{\lambda}=\left\{0.825+\frac{0.387\left(G_{r} P_{r}\right)^{1 / 6}}{\left[1+\left(0.492 / P_{r}\right)^{9 / 16}\right]^{8 / 27}}\right\}^{2}
$$

Based on the above model and formulas, the flow chart of thermal analysis is shown below in Fig.4.

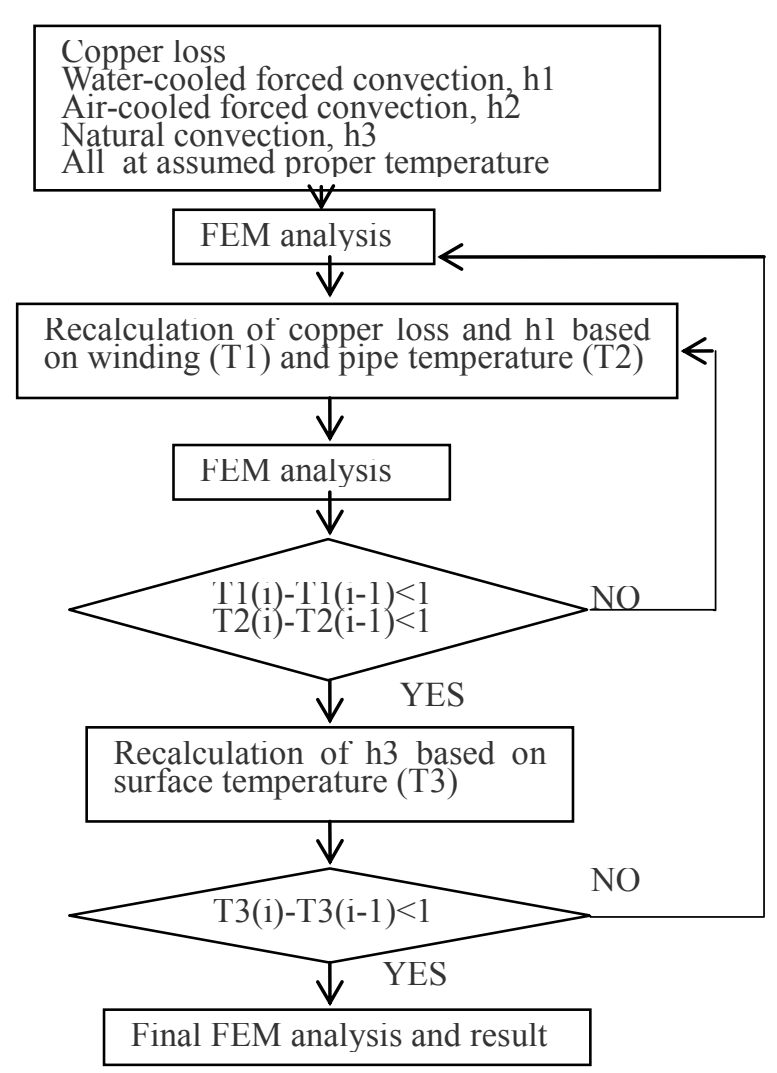

Fig. 4. Process of thermal analysis 


\subsection{Results and Discussion}

Primarily, thermal analysis focuses on the influence of water flow on the motor heat dissipation and force performance under different operation conditions, and the volumetric flow of water is optimized to continuous duty, short-time duty as well as intermittent duty. In addition, as to short-time duty, the maximum duration is calculated when applied with a certain large short-time current. Finally, as to intermittent duty, the optimal current as well as load time and standstill time are calculated to achieve the perfect thrust characteristic.

As to continuous duty, under the rated load $8 \mathrm{~A}$, the temperature rise of winding, the hottest and the coldest point with the variable water flow was investigated as shown in Fig.5 (a). Clearly, with the increase of water flow, the temperature rise of the motor is decreased, but the temperature reduction is not obvious when water flow is greater than $4 \mathrm{~L} / \mathrm{min}$. Fig.5 (b) illustrates the temperature distribution on the direction of the $y$-axis when $x$ equals $3.375 \mathrm{~mm}$ under differing water flow. Obviously, the high temperature gradients appear at the regions of insulation and air-gap. Thermal and thrust performance of the motor can be optimized through appropriate measures such as changing the insulating material and its distribution [1] or the thickness of the coil [6]. Similarly, the temperature reduction is not visible when water flow exceeds $4 \mathrm{~L} / \mathrm{min}$.

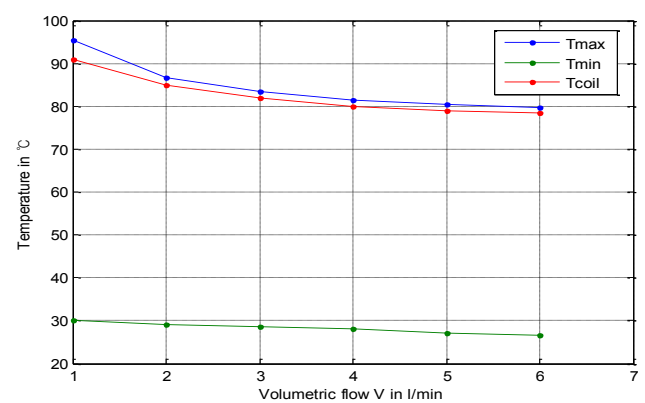

(a)Temperature of winding, the hottest and the coldest point

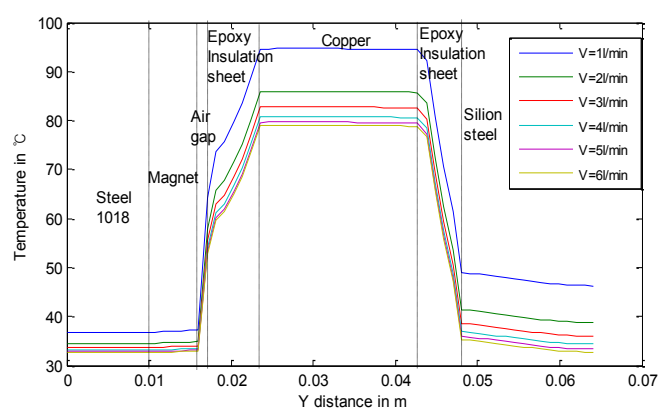

(b)Temperature in the y direction when $x=3.375 \mathrm{~mm}$

Fig. 5. $I=8 \mathrm{~A}$, temperatures variation with different water flow
As to the other two continuous conditions, the proper temperature of $120^{\circ} \mathrm{C}$ and the maximum temperature of $155^{\circ} \mathrm{C}$, the maximum allowable continuous operating current can be achieved under differing water flow as shown in Fig.6 (a). It can be found that the greater the water flow the bigger the allowable current in a certain temperature limit. When the water flow is increased to $4 \mathrm{~L} / \mathrm{min}$, the current can be approximately enhanced to $0.8 \mathrm{~A}$ However, the current increment is very small after $4 \mathrm{~L} / \mathrm{min}$. On the basis of the electromagnetic analysis results, thrust ripple and thrust ratio under the maximum permissible continuous current can be calculated as shown in Fig.6 (b). When the water flow increases to $4 \mathrm{~L} / \mathrm{min}$, the ratio was reduced by approximately $5.5 \%$ at the temperature rise limitation of $120^{\circ} \mathrm{C}$ and $5.9 \%$ at the temperature rise limitation of $155^{\circ} \mathrm{C}$, which greatly enhances the thrust performance of the motor.

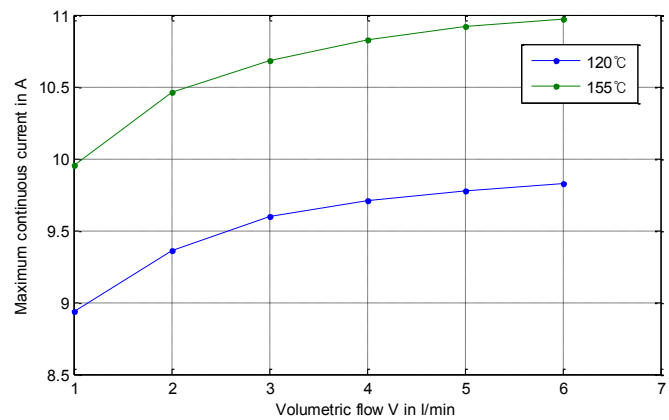

(a)The maximum allowed continuous current

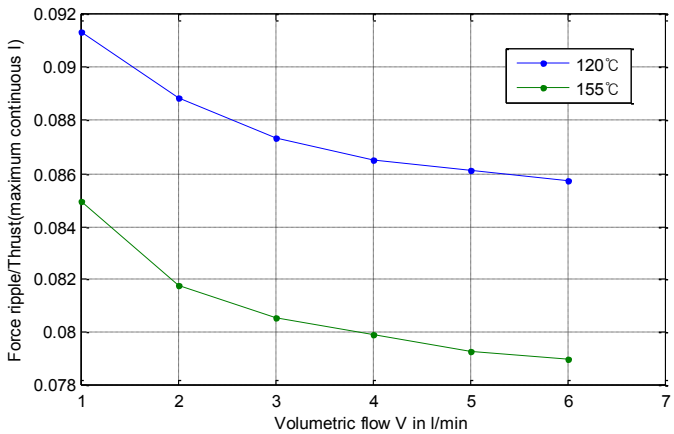

(b)The ratio of thrust ripple and thrust

Fig. 6. The maximum allowed continuous current and force Performance

As to short-time duty, the hottest point temperature is almost free from the variation of water flow, since an enormous short-term operating current contributes to a fast change in winding temperature rise, which quickly increases to the limitation of $155^{\circ} \mathrm{C}$. As shown in Fig.7 (a), with differing water flow, the variation regularity of the hottest temperature remained basically consistent at a short- 
term current of $24.7 \mathrm{~A}$. Then, $2 \mathrm{~L} / \mathrm{min}$ was specified to discover the relationship between the maximum allowed time and the short-time current shown in Fig.7 (b), which is a vital and practical reference in the actual operation. A larger short-time current leads to a shorter duration. It is worth noting that a blind pursuit of large current to expect big thrust is unreasonable because the thrust ripple rapidly rises linearly, and simultaneously the thrust growth becomes flat when the current density exceeds 14 . Therefore, the actual short-time current, duration and thrust requirements should be compromised.

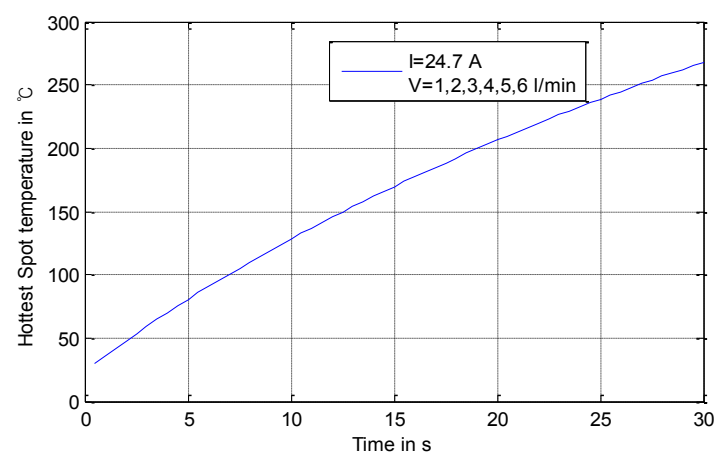

(a) $\mathrm{I}=24.7 \mathrm{~A}$, the hottest point temperature under different water flow

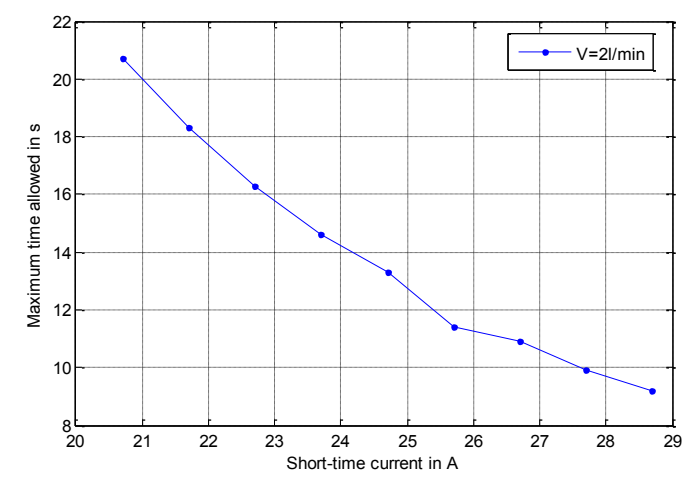

(b) Allowed time under different short-time current

Fig. 7. Thermal performance under short-time operation

As to intermittent duty, the variation of water flow has little effect on temperature rise, according to the simulation results, which have not been shown here specifically and $2 \mathrm{~L} / \mathrm{min}$ was specified. Load time with constant current alternates with a standstill time with no current. The motor heats up during load time and then cools down while at standstill time.

Fig.8 illustrates temperature variation of different parts of the motor. From the thrust and thrust ripple characteristic curve, the optimal current density 14 was adopted in order to get a minimum ratio of thrust ripple and thrust. Particularly, at the hottest point temperature oscillates between a maximum value $120^{\circ} \mathrm{C}$ and a minimum value $110^{\circ} \mathrm{C}$, which can be adjusted according to practical requirement. As shown, it is obvious that the hottest point temperature varies approximately periodically when it changes among $110^{\circ} \mathrm{C}-120^{\circ} \mathrm{C}$. Both load time and standstill time appear to be $4.5 \mathrm{~s}$. At $37.25 \mathrm{~s}$, the highest temperature reaches $120^{\circ} \mathrm{C}$, after which the current was set to zero until the temperature goes down to $110^{\circ} \mathrm{C}$, and so forth. Apparently, at the initial stage, winding temperature seems to increase linearly with time. Slot insulation, the armature yoke and armature teeth temperature rises slowly, but after a while ascends more and more quickly. Since the ideal heat source is copper loss and thermal conductivity of slot insulation material is so small, heat on the winding can not transmitted to the insulation and armature core quickly at first.

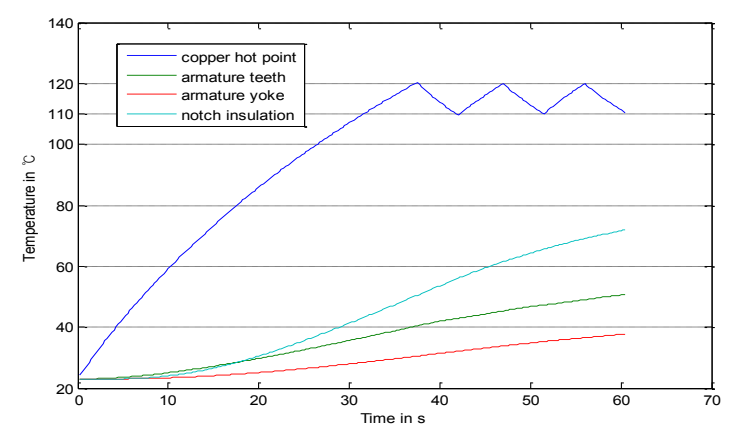

Fig. 8. Temperature variation, current density=14

\section{Conclusion}

Through joint electromagnetic and thermal analysis, some valuable discoveries are summarized as follows:

1) Water is critical to dramatically reducing temperature rise and enhancing the motor output, without which winding temperature rises up to $120^{\circ} \mathrm{C}$. As well, the maximum allowed current is $4.43 \mathrm{~A}$ with a temperature rise of $120^{\circ} \mathrm{C}$. But it approximately decreases to $90^{\circ} \mathrm{C}$ with water cooling.

2) A big current may not contribute to superior thrust performance. Thrust appears as a slow increase and force ripple emerges as a remarkable growth when current density exceeds 14. According to thrust property and temperature rise, a reasonable current density can be selected.

3) As for continuous operation conditions, water flow variation has a quite obvious effect on thermal and thrust performance. $4 \mathrm{~L} / \mathrm{min}$ is optimal due to dramatically reduce the temperature rise, the ratio of thrust ripple and thrust with a relatively small noise and water pressure. 
4) As for short-time operation conditions, the hottest point temperature is almost free from the changes of water flow. A larger short-time current leads to a shorter duration. The actual short-time current, duration and thrust should be compromised virtually.

5) As for intermittent operation conditions, the change of water flow has little effect on the hottest spot temperature rise. In practical application, the optimal current and the perfect performance can be achieved through determining the distribution of cycle time appropriately.

\section{Acknowledgements}

This work was supported by the National Natural Science Foundation of China (NSFC51077115, 51277158) and Zhejiang Provincial Natural Science Foundation of China (R1110033).

\section{References}

[1] Changsoo Jang, Jong Young Kim, Yung Joon Kim, Jae Ok Kim, "Heat Transfer Analysis and Simplified Thermal Resistance Modeling of Linear Motor Driven Stages for SMT Applications," IEEE Trans. Components and packaging Technologies, Vol. 26, No. 3, September 2003 pp.532 - 540.

[2] Nattapon Chayopitak, David G. Taylor, "Thermal Analysis of Linear Variable Reluctance Motor for Manufacturing Automation Applications," IEEE International Conference. Electric Machines and Drives, May 2005 pp.866- 873.

[3] Aldo Boglietti, Andrea Cavagnino, David Staton,Martin Shanel, Markus Mueller, Carlos Mejuto, "Evolution and Modern Approaches for Thermal Analysis of Electrical Machines," IEEE Trans. Industrial Electronics, Vol. 56, No. 3, March 2009 pp.871 - 882 .

[4] Ximin Zhang, Zepei Ren, Feiming Mei, "Heat Transfer Theory", China building industry press. July 2007.

[5] Frank P.Incropera, David P. DeWitt, "Introduction to heat transfer -Third edition-“, School of Mechanical Engineering Purdue.

[6] Ho-Jin An, Ji-Hyun Kim, Ki-Bong Jang, Gyu-Tak Kim, "Optimal Current Density with Coil Thickness of Double Sided Permanent Magnet Linear Synchronous Motor (PMLSM)", Department of Electrical Engineering, Changwon National University.

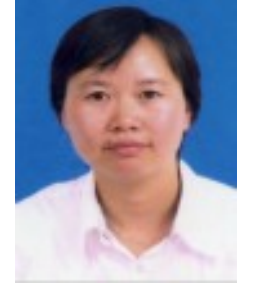

Qinfen Lu received his B.E. degree, M.E. degree and $\mathrm{Ph}$. D. degree from Zhejiang University, Hangzhou, China, in 1996, 1999 and 2005, respectively. Since 1999, she has been with the College of Electrical Engineering, Zhejiang University, where she is currently an associate professor. Her research interests include analysis and control of linear machines, PM machines, etc.

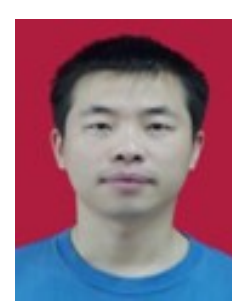

machines.

Chuanying Cheng graduated from the Second Artillery Engineering College, Xi'an, China, in 2004. Since 2010, he has been in the College of ElectricaEngineering, Zhejiang University, where he is studying for his M.E. degree. His research interests include magnetic analysis of linear

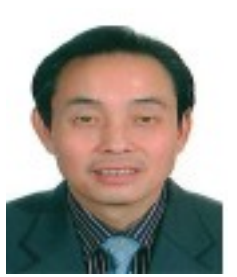

Yunyue Ye graduated in Zhejiang University, Hangzhou, China, in 1978. Since 1978, he has been with the College of Electrical Engineering, Zhejiang University, where he has been a Professor since 2000. His research interests include linear machines, direct driven motor, optimal design, and modern driven technology.

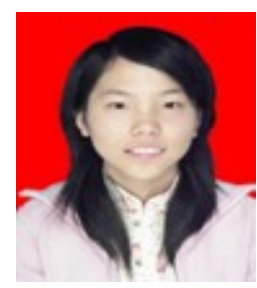

machines.
Xinmin Zhang received her B.E. degree from Hunan University, Changsha, China, in 2011. Since 2011, she has been in the College of Electrical Engineering, Zhejiang University, where she is studying for her M.E. degree. Her research interests include magnetic and thermal analysis of linear 